\title{
Impact of Replacing Old C-Arms on Reducing Radiation Exposure
}

\author{
Gordon T. Robbins ${ }^{1}$ Nicholas J. Wellnitz ${ }^{2}$ Peter E. Darwin ${ }^{3}$ \\ ${ }^{1}$ Department of Medicine, Division of Gastroenterology and \\ Hepatology, University of Maryland Medical Center, Baltimore, \\ Maryland, United States \\ 2 Department of Radiation Safety, University of Maryland, Baltimore, \\ Maryland, United States \\ 3 Department of Medicine, Division of Gastroenterology and \\ Hepatology, University of Maryland School of Medicine, Baltimore, \\ Maryland, United States
}

\author{
Address for correspondence Gordon T. Robbins, MD, 22 South \\ Greene Street, Baltimore, MD, 21201, United States \\ (e-mail: GRobbins@som.umaryland.edu).
}

J Gastrointestinal Abdominal Radiol ISGAR 2022;5:222-224.

\begin{abstract}
Fluoroscopy is increasingly used by gastroenterologists for endoscopic procedures such as endoscopic retrograde cholangiopancreatography. Unfortunately, fluoroscopy exposes patients and staff to ionizing radiation, which can cause DNA damage, cell death, genetic defects, and cancer. These adverse effects are more likely to occur with increased exposure time and higher radiation doses; therefore, all efforts to decrease exposure are helpful. In this study, we investigate the impact that updating the C-Arms in our endoscopy unit will have on radiation exposure by comparing ionizing radiation effects of the OEC 9900 Elite to the newer OEC Elite. After replicating the setup of a typical endoscopic retrograde cholangiopancreatography, ionizing radiation and energy were measured at the bedside and the head of the bed with each machine. At both positions, the newer OEC Elite C-Arm emitted less energy and ionizing radiation than the OEC 9900 Elite. Continuous imaging with OEC 9900 Elite emitted $0.12 \mathrm{mSv} / \mathrm{h}$ at the head of the bed and $0.49 \mathrm{mSv} / \mathrm{h}$ at the bedside, while the OEC Elite only emitted

Keywords

- Endoscopic retrograde cholangiopancreatography

- fluoroscopy

- ionizing radiation

- radiation $0.04 \mathrm{mSv} / \mathrm{h}$ and $0.14 \mathrm{mSv} / \mathrm{h}$, respectively. These values are measures of radiationinduced cancer risk, otherwise known as stochastic risk. The differences grow more significant when extrapolated to show radiation differences for an average procedure (approximately 8 minutes of fluoroscopy time) and the procedural volume for an entire year. In an effort to use as little radiation as possible, we see that we can significantly reduce radiation exposure to our staff by upgrading from an OEC 9900 Elite to and OEC Elite.
\end{abstract}

\section{Introduction}

Fluoroscopy guidance is widely employed in the field of gastroenterology, particularly by specially trained gastro- enterologists for endoscopic retrograde cholangiopancreatography (ERCP), a procedure with diagnostic and therapeutic benefits in pancreatobiliary disease. A C-arm is an intraoperative source of fluoroscopic X-ray, named for its published online January 28, 2022
DOI https://doi.org/

10.1055/s-0041-1740476.

ISSN 2581-9933.

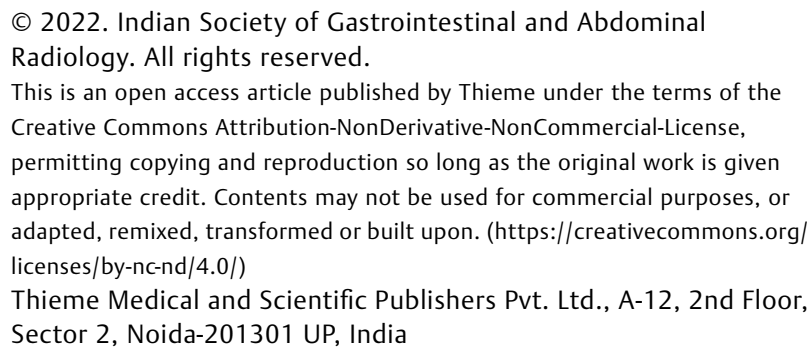

(c) 2022. Indian Society of Gastrointestinal and Abdominal Radiology. All rights reserved.

This is an open access article published by Thieme under the terms of the Creative Commons Attribution-NonDerivative-NonCommercial-License, permitting copying and reproduction so long as the original work is given appropriate credit. Contents may not be used for commercial purposes, or adapted, remixed, transformed or built upon. (https://creativecommons.org/ licenses/by-nc-nd/4.0/)

Thieme Medical and Scientific Publishers Pvt. Ltd., A-12, 2nd Floor, Sector 2, Noida-201301 UP, India 

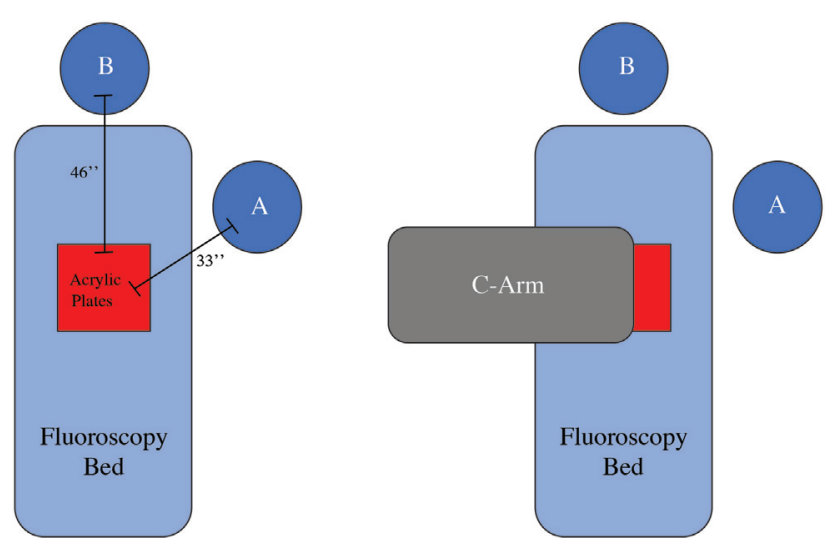

Fig. 1 Room Arrangement, with and without C-Arm. This figure illustrates the spatial arrangement used in our study to replicate a typical ERCP with the locations of radiation measurement marked by letters A and B. On the left, the layout is shown without the C-Arm in place. On the right, the setup is complete with the C-Arm in location for obtaining data. ERCP, endoscopic retrograde cholangiopancreatography.

C-shaped body. When performing an ERCP, a C-Arm is placed adjacent to a patient's bed so that the X-ray source is below the patient and an X-ray detector is above the patient. Unfortunately, this comes with the risk of ionizing radiation to all those involved in the case, including endoscopists, anesthesiologists, anesthetists, nurses, and techs working in close proximity to the scattered radiation from the patient. Ionization can cause DNA damage and cell death, leading to cancer and genetic defects. The longer the radiation exposure and the higher the radiation levels, the more likely one is to experience these consequences. Thus, the Nuclear Regulatory Commission (NRC) set an occupational dose limit of 50 millisievert (mSv) effective doses per year. ${ }^{1}$ On average, an endoscopist receives an effective dose of $0.07 \mathrm{mSv}$ per ERCP, which uses approximately 8 minutes of fluoroscopy time., ${ }^{2,3}$ While this effective dose is small in relation to the annual dose limit, some of the most serious adverse effects of radiation, including those mentioned above, can occur with any level of exposure. ${ }^{2}$ Studies have demonstrated the benefit of protective equipment but this is subject to improper use and inconsistency by the user. The most effective way to mitigate exposure would obviously be to reduce emissions. Our study investigates the effect that updating our C-Arm will have on radiation exposure by comparing the ionizing radiation effects of the OEC 9900 Elite to the newer OEC Elite.

\section{Methods}

We replicated the layout of a typical ERCP in our endoscopy suite with a C-Arm adjacent to a fluoroscopy bed containing a stack of acrylic plates to simulate our patient and create radiation scatter (-Fig. 1). Using a Fluke 451 Ion Chamber Survey Meter, we measured energy output in Kilovoltage peak $(\mathrm{kVp})$ and Milliamperage (ma) and levels of radiation in the air as milliroentgen per hour $(\mathrm{mR} / \mathrm{h})$. Measurements were obtained at the bedside, 33 inches from the center of the bed to simulate the position of the endoscopist and at the head of the table, 46 inches from the center of the bed to simulate the position of the anesthetist. The same arrangement and measurements were completed with the OEC 9900 Elite and the OEC Elite. For each C-Arm and position, we calculated $\mathrm{mSv} / \mathrm{h}$ with continuous and pulsed fluoroscopy. Millisievert per hour can easily be calculated from milliroentgen per hour $(\mathrm{mR} / \mathrm{h})$ as $1.0 \mathrm{mR}$ is equal to $0.0087 \mathrm{mSv}$.

\section{Results}

At each position, the OEC Elite emitted less energy and ionizing radiation or potential for radiation-induced harm than the OEC 9900 Elite. Continuous imaging with OEC 9900 Elite emitted $0.12 \mathrm{mSv} / \mathrm{h}$ at the head of the bed and 0.49 $\mathrm{mSv} / \mathrm{h}$ at the bedside, while the OEC Elite emitted only 0.04 $\mathrm{mSv} / \mathrm{h}$ and $0.14 \mathrm{mSv} / \mathrm{h}$, respectively (-Table $\mathbf{1}$ ). With pulsed imaging, the differences between the OEC 9900 Elite and OEC Elite were smaller; however, the OEC Elite still emitted less radiation at both locations.

\section{Discussion}

With an average of 8 minutes of fluoroscopy time per ERCP and $\sim 850$ ERCP cases done annually in our endoscopy center, these differences become more significant. Continuous fluoroscopy imaging with OEC 9900 Elite produces $13.92 \mathrm{mSv} /$ year at the head of the bed and $55.60 \mathrm{mSv} / \mathrm{year}$ at the bedside ( - Table 2). However, the OEC Elite produces $4.18 \mathrm{mSv} /$ year and 15.41

Table 1 Energy output and stochastic risk of each C-arm

\begin{tabular}{|l|l|l|l|l|l|l|l|l|}
\hline & \multicolumn{2}{l|}{ OEC 9900 Elite } & \multicolumn{2}{l|}{ OEC Elite } \\
\hline & Head of bed (46") & \multicolumn{2}{l|}{ Bedside (33") } & \multicolumn{2}{l|}{ Head of bed (46") } & \multicolumn{2}{l|}{ Bedside (33") } \\
\hline & Continuous & Pulse & Continuous & Pulse & Continuous & Pulse & Continuous & Pulse \\
\hline $\mathrm{mR} / \mathrm{h}$ & 14.0 & 3.4 & 56.0 & 11.4 & 4.2 & 2.90 & 15.5 & 10.2 \\
\hline $\mathrm{mSv} / \mathrm{h}$ & 0.123 & 0.030 & 0.491 & 0.100 & 0.037 & 0.025 & 0.136 & 0.089 \\
\hline $\mathrm{kVp}$ & 71.0 & 74.0 & 71.0 & 75.0 & 62.0 & 61.0 & 62.0 & 61.0 \\
\hline $\mathrm{mA}$ & 2.3 & 2.5 & 2.3 & 2.5 & 1.8 & 4.7 & 1.7 & 4.7 \\
\hline
\end{tabular}

Abbreviations: kVp, Kilovoltage peak; mA, milliamperage; mR/h, milliroentgen per hour; mSv/h, milliSievert per hour.

Note: This table depicts the energy output in $\mathrm{kVp}$ and $\mathrm{mA}$ as well as the measurement of radiation in a volume of air ( $\mathrm{mR} / \mathrm{h}$ ) with the associated stochastic biological risk (mSv/h) for each device, image mode, and location. 
Table 2 Risk of ionizing radiation associated with endoscopic retrograde cholangiopancreatography

\begin{tabular}{|c|c|c|c|c|c|c|c|c|}
\hline & \multicolumn{4}{|c|}{ OEC 9900 Elite } & \multicolumn{4}{|l|}{ OEC Elite } \\
\hline & \multicolumn{2}{|c|}{ Head of bed (46") } & \multicolumn{2}{|c|}{ Bedside (33") } & \multicolumn{2}{|c|}{ Head of bed (46") } & \multicolumn{2}{|c|}{ Bedside (33") } \\
\hline & Continuous & Pulse & Continuous & Pulse & Continuous & Pulse & Continuous & Pulse \\
\hline $\mathrm{mSv} / \mathrm{h}$ & 0.123 & 0.030 & 0.491 & 0.100 & 0.037 & 0.025 & 0.136 & 0.089 \\
\hline $\mathrm{mSv} /$ case & 0.016 & 0.004 & 0.065 & 0.013 & 0.005 & 0.003 & 0.018 & 0.012 \\
\hline mSv/year & 13.915 & 3.379 & 55.660 & 11.331 & 4.175 & 2.882 & 15.406 & 10.138 \\
\hline
\end{tabular}

Abbreviation: ERCP, endoscopic retrograde cholangiopancreatography.

Note: This table depicts stochastic biological risk of ionizing radiation in rates of millisievert. These values are shown in rates per hour, case, and year. In this study, a case represents 8 minutes of fluoroscopy time, which is the average amount needed for one ERCP. A year consists of 850 ERCP cases, which is the approximate ERCP case load in our Endoscopy Center.

$\mathrm{mSv} /$ year at respective locations. Our measurements in this study are not "effective doses" as they are not the weighted sums of radiation doses on relevant organs and tissues, thus they cannot be readily compared with the annual effective dose limit set by the NRC. Instead, they serve to demonstrate the difference in ionizing radiation at one point in space, which is a surrogate to show that annual ionizing radiation dose and stochastic biological risk (radiation-induced cancer risk) are strongly influenced by C-Arm choice.

\section{Conclusion}

This study supports the well-established principle that the greater the distance at which a staff member stands from the location from where X-rays enter the patient, the lower their radiation exposure will be. Similarly, using pulsed imaging mode lowers scatter radiation exposure. Unique to this study is the demonstration that the OEC Elite operated at a lower energy output ( $\mathrm{kVp}$ and $\mathrm{mA}$ ) than the OEC 9900 Elite, which resulted in lower scatter radiation exposure. While the radiation dose per ERCP case with either C-Arm in our study seems relatively low, particularly when compared with the annual effective dose limit, endoscopists should be adopting the practice of "as low as reasonably achievable." This is a widely accepted principle in the field of radiation safety, encouraged by national and international radiation safety agencies. ${ }^{4}$ In all avenues, it is a good practice to use the least amount of radiation to get the results, data, and images deemed necessary to complete an intervention. In this case, we have strong evidence to suggest that you can reduce exposure to radiation by upgrading from an OEC 9900 Elite to an OEC Elite.

\section{Funding \\ None.}

Conflict of Interest

None declared.

\section{References}

1 Backgrounder on Biological Effects of Radiation. United States Nuclear Regulatory Commission website. Updated July 7, 2020. Accessed September 25, 2020 at: https://www.nrc.gov/reading-rm/doc-collections/fact-sheets/bio-effects-radiation.html

2 Uradomo L, Cohen H, Fried M, Petrini J, Rehani M. Radiation protection in the endoscopy suite minimizing radiation exposure for patients and staff in endoscopy: a joint ASGE/IAEA/WGO guideline. Arab J Gastroenterol 2010;11:116-119

3 Kim KP, Miller DL, Berrington de Gonzalez A, et al. Occupational radiation doses to operators performing fluoroscopically-guided procedures. Health Phys 2012;103(01):80-99

4 Standards for protection against radiation-Nuclear Regulatory Commission. Final rule. Fed Regist 1991;56(98):23360-23474 